\title{
SEISMIC SOURCE FUNCTIONS AND ATTENUATION FROM LOCAL AND TELESEISMIC OBSERVATIONS OF THE NTS EVENTS JORUM AND HANDLEY
}

\author{
By Donald V. Helmberger and David M. Hadley
}

\begin{abstract}
Several strong-motion seismograms recorded at $8 \mathrm{~km}$ from a large nuclear test at Pahute Mesa, Nevada Test Site, are modeled using the Cagniard-de Hoop technique. The ratio of vertical to radial motions suggest that the peak values are produced by ray paths that penetrated to a depth several kilometers below the source. A homogeneous layered Earth model with velocity increasing with depth was used in the modeling of the velocity time histories. The upper portion of the velocity model was determined by averaging bore-hole data and the lower portion was obtained from regional refraction measurements. Assuming a modified Haskell (1967) source representation,
\end{abstract}

$$
\psi(t)=\psi_{0}\left[1-e^{-\kappa t}\left(1+K t+(K t)^{2} / 2-B(K t)^{3}\right)\right]
$$

we obtain a range of source descriptions with $\psi_{0}$ varying with $K$ and $B, \psi_{0}(K, B)$. The range of source models for Jorum are $\psi_{0}(5,1)=3.1, \psi_{0}(5,2)=1.7$, and $\psi_{0}(5,3)=1.2$ times $10^{11} \mathrm{~cm}^{3}$, respectively. Given an explosion source description, it is a straightforward task to determine the teleseismic attenuation from WWSSN observations. From both the short- and long-period observations from these events, an average $t^{*}$ of 1.3 is obtained for compressional waves of a dominant 1-sec period. This estimate is insensitive to the range of $K$ and $B$ obtained from the near-field modeling.

\section{INTRODUCTION}

In recent years, a number of authors have compared sources derived from local strong motion data with teleseismic observations. In the case of explosions, investigators have examined the frequency content of short-period $P$ waves to measure attenuation (e.g., Frasier and Filson, 1972). They estimate $t_{\alpha}{ }^{*}$ to be about 0.5 where $t_{\alpha}{ }^{*}=\frac{T}{Q_{\alpha}}$ with $T$ the travel time of compressional $(\alpha)$ waves and $Q_{\alpha}$ the quality factor. If $t^{*}$ is known along some ray path, then a convolution operator $A\left(r, t^{*}\right)$ can be constructed to correct a seismic pulse for attenuation [Carpenter et al. (1967)].

In the case of earthquake data, occasionally both long- and short-period $P$ and $S$ waves at teleseismic distances and well-recorded local $S$ waves are available. The long-period pulses are easily modeled synthetically. For example, the results of Burdick and Mellman (1976) for the Borrego Mountain earthquake indicate that the direct $P$ wave actually contains $P, p P$, and $s P$, with the latter phase dominating. Modeling the phases $s P$ and $s S$ from the Borrego Mountain earthquake, Burdick (1978) estimated $t_{\beta}{ }^{*}$ to be 5.2 where the $\beta$ refers to shear waves. Heaton and Helmberger (1977) modeled the strong-motion data and found that Burdick's teleseismic description of Borrego was compatible with the local observations.

In general, comparing seismic pulses at various locations produced by earthquakes with the intent of determining $Q$ is particularly difficult because of source finiteness and associated directivity effects. The complex radiation pattern associated with earthquakes introduces large uncertainties in comparing waveforms from various 
stations. With the goal of avoiding this problem, we have reworked some of the best data available for comparing observations made near large nuclear explosions with teleseismic measurements of short- and long-period $P$ waves.

\section{Near-Field Studies}

The megaton events, Handley and Jorum, considered in this study were located on the Pahute Mesa of the Nevada Test Site (NTS), see Figure 1. The near-field data described by Peppin (1974) were recorded at several azimuths at a distance of $8 \mathrm{~km}$. These data provide a reversed profile with Jorum shooting west and Handley toward the east. For this size event, recordings at $8 \mathrm{~km}$ probably better represent the source than would closer recordings. Near-source effects such as triggered movement on nearby joints should not dominate the observations and the recording site is less likely to be in the zone of nonlinear deformation. Seismograms recorded

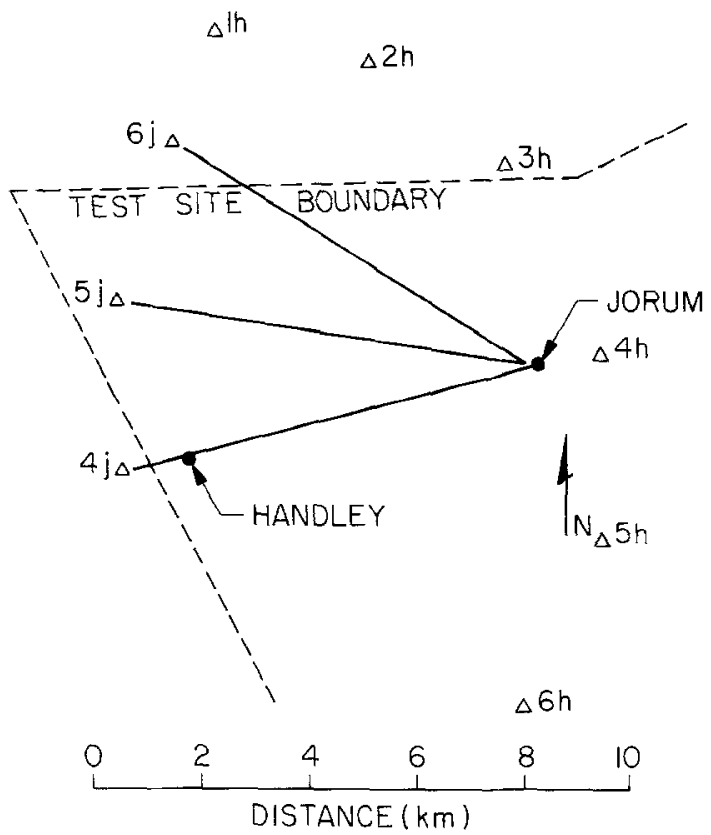

Fig. 1. Map of NTS showing accelerometer locations, $\Delta_{f}$ (Jorum), $\Delta_{h}$ (Handley), for the Jorum and Handley tests, modified from Peppin (1974).

from the Jorum experiment are shown in Figure 2; however, the reverse Handley experiment was not as successful. The records are similar to those in Figure 2, but are slightly clipped on the first downswing (Peppin, 1974). An amplitude plot of the first peak of the Handley data shows less variation than those of Figure 2, although the average acceleration is greater (Stump, 1979). Viewing the results of the two experiments as a whole, we see some variations with azimuth. However, given the uncertainty in the Earth model near the sites, the Jorum data appear to be representative of the observed motions.

The energy in the first arrivals at stations 4 to 6 , (Figure 2) is concentrated on the vertical component but, as time progresses, shifts to the radial. Also, note that many of the later arrivals are not particularly coherent from site to site, as can be seen by comparing any individual trace with the average stack shown on the bottom of Figure 2. The initial features can be explained by an initial downgoing $P$ wave, with 
an incidence angle at the stations of about $30^{\circ}$ yielding a radial to vertical ratio of about 0.4 . The later arrivals probably contain abundant information about the source-surface interaction, slapdown, tectonic release, slippage along cracks, and other complex phenomena. This study will concentrate on the first cycle of motion
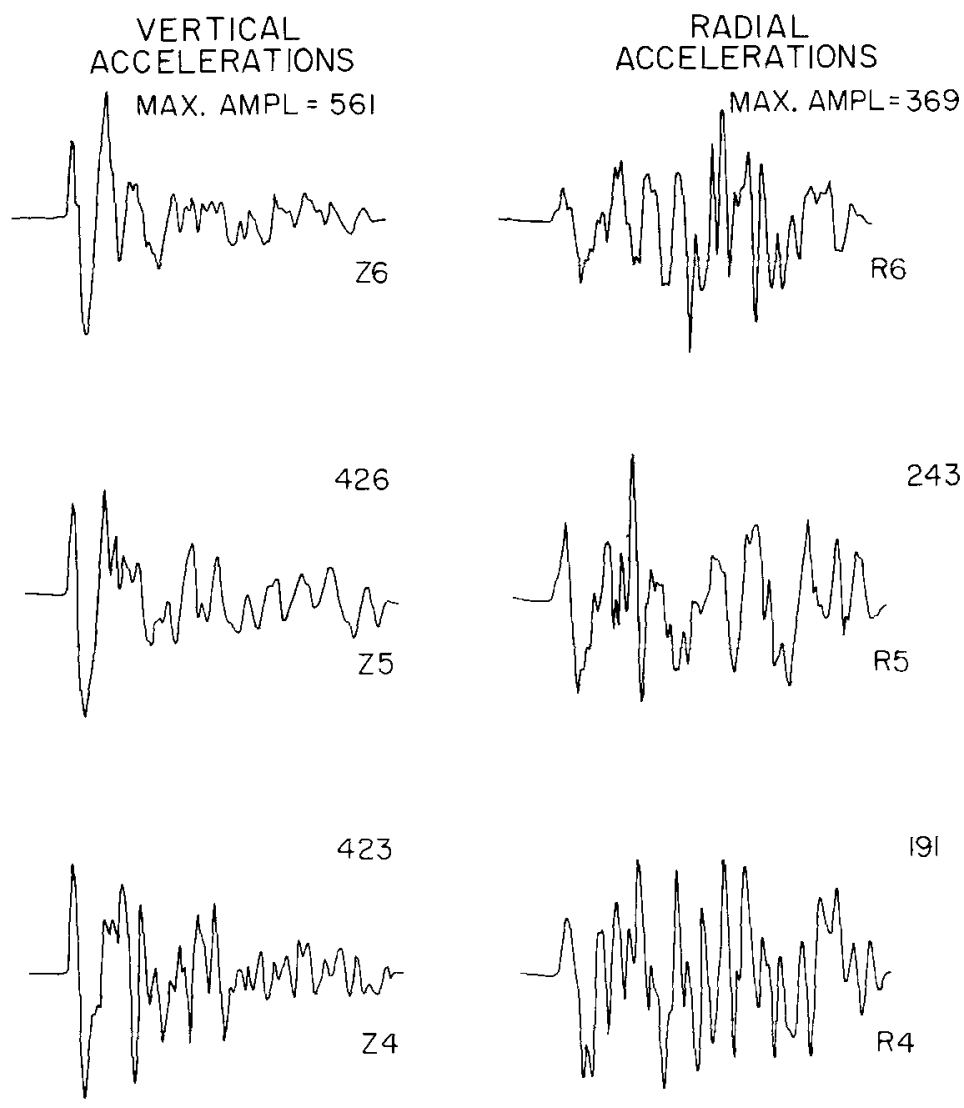

$|9|$
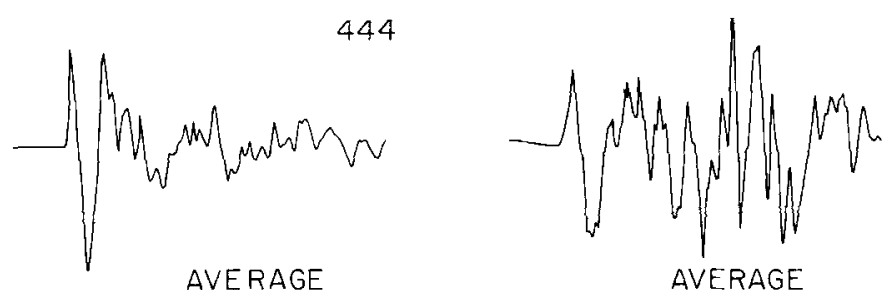

$|8|$

AVERAGE

2 $\sec$

Fig 2. Vertical and radial accelerograms at sites 6,5 , and 4 with peak amplitudes given above each trace. The bottom traces are the stacked averages of the vertical and radial components, respectively. The number above each trace indicates the peak amplitude in $\mathrm{cm} / \mathrm{sec}^{2}$.

which is interpreted as representative of the dominant outgoing signals. For modeling purposes, it is convenient to work with the integral of these acceleration measurements as displayed in Figure 3. The slight linear drift that results from integration of the record has not been removed because we will work with only the 
first cycle. Furthermore, the instruments are sufficiently broadband that the initial velocity pulse can be treated as the true ground motion (McEvilly, personal communication). Thus, the first second of the average vertical velocity component of the local recordings along with the corresponding teleseismic observations (Figure 4) will be the prime data set for determining $t^{*}$.

VERTICAL VELOCITY
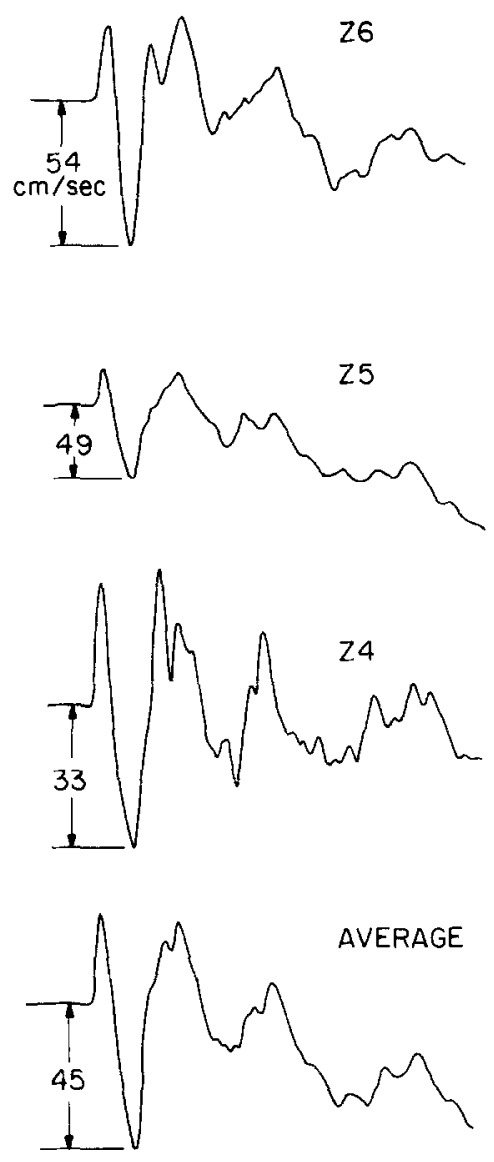

RADIAL VELOCITY
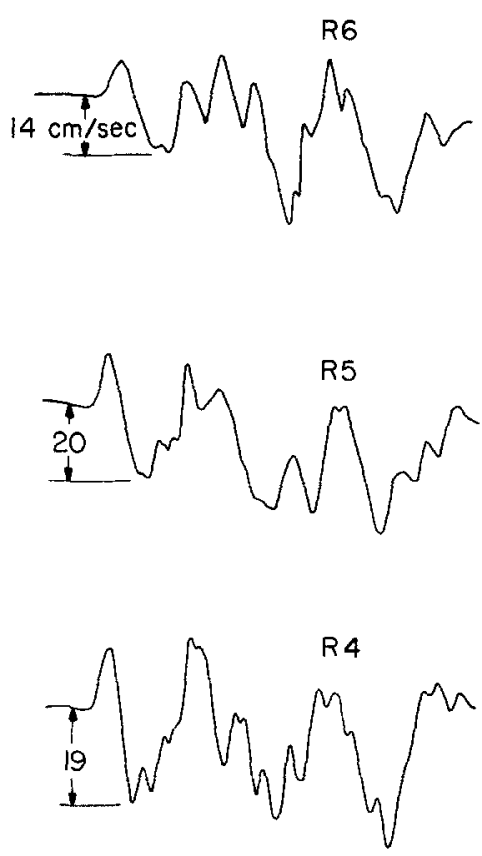

AVERAGE

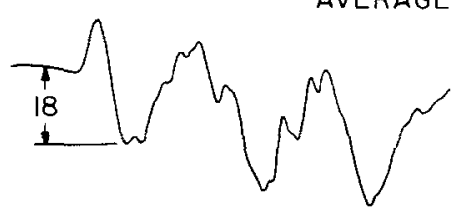

\section{$\begin{array}{lll}0 & 1 & 2 \\ 1 & 1 & \end{array}$}

FIG. 3. Vertıcal and radial velocities obtained by integratıng the accelerograms displayed in Figure 2

\section{Near-Field Modeling Techniques}

The techniques for modeling teleseismic explosion waveforms have been discussed at length by numerous authors with one of the latest expositions being given by Burdick and Helmberger (1979). Assuming an elastic layered earth with $t^{*}=1$, they find that large overshoots of at least 2 to 1 in the reduced displacement potential, RDP, will explain most of the short- and long-period observations of both the Soviet and United States explosions. The Burdick and Helmberger study used 
the form of RDP proposed by von Seggern and Blandford (1972) expressed by

$$
\psi(t)=\psi(\infty)\left[1-e^{-K t}\left(1+K t-B(K t)^{2}\right)\right]
$$

where $\psi(\infty)$ is the source strength, $K$ scales inversely as the cube root of the yield,

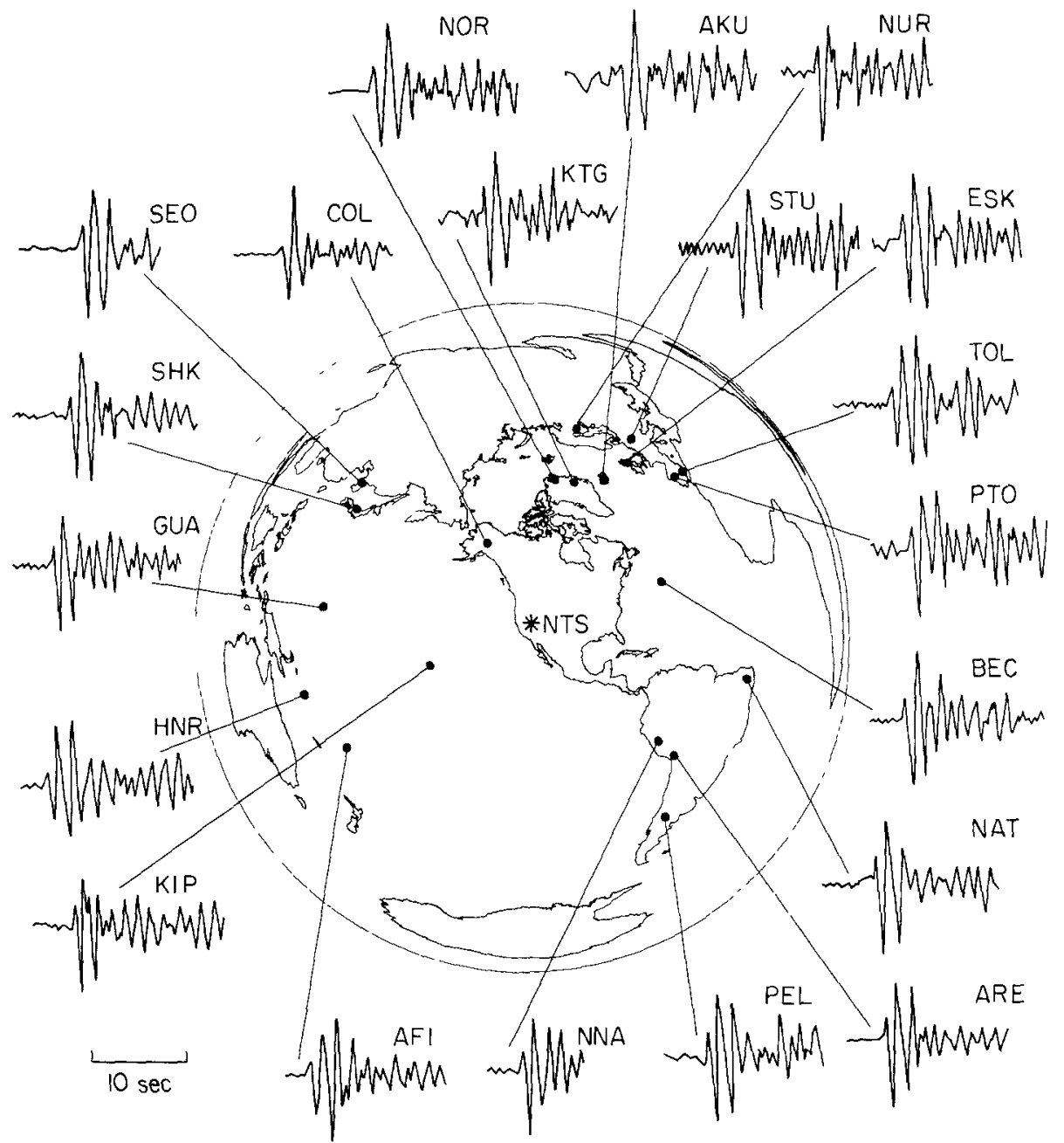

FIG. 4. Station Iocation and $P$ waves obtained from the WWSSN. Absolute amplitude data are listed in Table 1.

and $B$ is the overshoot constant. With $B>2$ the data discussed by Burdick and Helmberger is well modeled without adding a slapdown phase or related phenomena. It should be noted that, in this study, the phase $p P$ is treated as a purely elastic interaction with the free surface. For the source depth of interest, this phase arrives during the latter half of the direct $P$ arrival. Hence, the overshoot behavior of the source and the phase $p P$ must add together to describe the observed phases. Because of the inherent trade-off, it is not possible to uniquely separate the real overshoot of the source from any nonlinear behavior of $p P$. 
The displacement potential is given by

$$
\phi(R, t)=-\psi(t) / R
$$

and the displacement by

$$
D(R, t)=\psi(t) / R^{2}+(1 / R \alpha) d \psi(t) / d t,
$$

where $R$ is the radial distance and $\alpha$ is the velocity. In terms of generalized ray theory, the vertical displacement (positive upward) for a layered Earth becomes

$$
D(r, \dot{z}, t)=(d \psi / d t * d S / d t)
$$

where the * signifies convolution. The step response of the model is given by

$$
S(t)=\frac{2}{r} \frac{1}{\pi}\left[\frac{1}{\sqrt{t}} * \sum \text { rays }\right]
$$

see (Helmberger and Harkrider, 1972). The velocity component can be written as

$$
\begin{aligned}
V(t) & =\frac{d}{d t}(d \psi / d t * d S / d t) \\
& =\left(d^{2} \psi / d t^{2} * d S / d t\right) \\
& =\left(d^{3} \psi / d t^{3} * S\right) \\
& =\frac{d}{d t}\left(d^{2} \psi / d t^{2} * S\right) .
\end{aligned}
$$

Mathematically, (6) through (9) are equivalents. However, each has a different physical significance. The derivative increases the high-frequency content of the operator by a factor of $\omega$. At teleseismic distances, the delta response of the Earth, $d S / d t$, is reasonably well known and thus, expression (6) is commonly used. For this reason, one does not worry about the fact that $\left(d^{2} \psi / d t^{2}\right)$ of the expression (1) is ill behaved. In the present study, the local structure at Jorum is not particularly well known and consequently, the knowledge of $S(t)$ at the short-periods is lacking and the operation $(d S / d t)$ should be avoided. This can be accomplished by demanding more of $\psi(t)$ or by adding another term in the von Seggern-Blandford (1972) description, as shown below

$$
\text { at } \psi(t)=\psi_{0}\left[1-e^{-K t}\left(1+(K t)+1 / 2(K t)^{2}-B(K t)^{3}\right)\right]
$$

and applying (9) in modeling the velocity pulses displayed in Figure 3. This source description is intermediate between Haskell (1967) and von Seggern and Blandford (1972). Haskell assumed a source function that resulted in continuous accelerations. His model has a far-field high-frequency behavior of $\omega^{-4}$. Von Seggern and Blandford found that $\omega^{-2}$ was a better description of the teleseismic data from Longshot, Milrow, and Cannikin. For this study, it is extremely useful to have velocity continuous. If we were attempting to model the high-frequency behavior of the teleseismic data, frequency $\sim 3$ to $4 \mathrm{~Hz}$, this distinction would be significant. However, since the derived source description will be used for only the longer 
periods, 1 to $2 \mathrm{sec}$, this difference is not particularly important. To compute $S(t)$, we need to have an accurate layered model of the source region, which is considered next.

\section{Local Crustal Model}

A detailed velocity model of the Silent Canyon Caldera and Pahute Mesa would be rather complex. With increasing depth, the lithological units grade from bedded and ash flow tuffs to interbedded tuffs and lava flows to lavas and intrusives with intermediate composition (Orkild et al., 1969). We have attempted to represent this complex with a four-layer model, Figure 5 . The surficial layer is an average velocity from an acoustic log obtained in a shallow borehole in the Oak-Spring tuff at the NTS (Keller, 1960). The bottom of this unit coincides with the position of the static water table (Springer and Kinnaman, 1971). The velocities of the next two units (3.4 and $3.8 \mathrm{~km} / \mathrm{sec}$ ) are consistent with a decrease in the tuff content with increasing depth and the report by Spence (1974) of an average caldera velocity of $3.6 \mathrm{~km} / \mathrm{sec}$. Finally, the velocity of the half-space is intermediate between the velocity of the pre-Cenozoic rocks that surround Pahute Mesa and the lavas and intrusions comprising the lower sections of the caldera (Spence, 1974; Diment et al., 1960). Depth to the top of this layer is approximately determined from geological sections constructed from borehole data (Orkild et al., 1969).

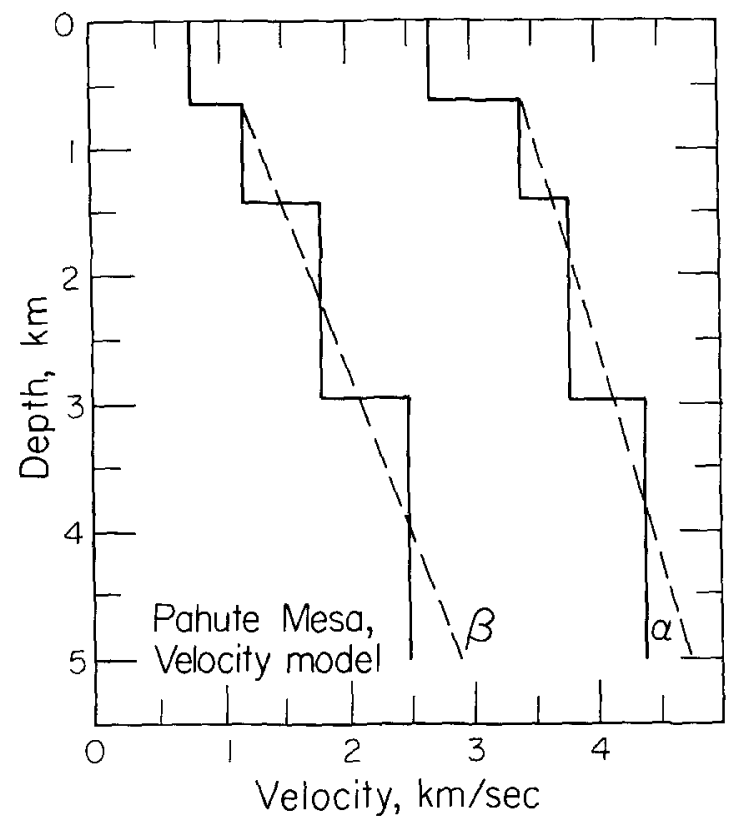

Fig 5 Crustal models constructed for the Pahute Mesa test site. The hard top model referred to in the text assumes that $\beta_{1}=\beta_{2}=12 \mathrm{~km} / \mathrm{sec}$, i.e., no change in shear velocity above a depth of $1.5 \mathrm{~km}$. The densities are from top to bottom, $2.6,27,2.8$, and $2.82 \mathrm{gm} / \mathrm{cm}^{3}$, respectively.

The $S$-wave velocity structures of the caldera region are not well constrained. The $S$-wave model shown in Figure 5 is a simple estimate based on the available $P$ wave data. The most important aspect of the $S$-wave model is the velocity of the topmost layer: a low $S$-wave velocity increases the strength of the phase, $p P$. Synthetic seismograms for a modified velocity structure with a higher surface $S$ wave velocity are also discussed below. This model replaces the surface $S$-wave velocity with that of the second layer. 


\section{Modeling the Strong-Motion Records}

Synthetic velocity waveforms based on the above model for a range of distances are presented in Figure 6. The transfer function, $d S / d t$, is included to display the roughness of the response caused by the layering. Note that in the synthetic velocity waveforms the phase $p P$, which becomes a strong feature beyond about $5 \mathrm{~km}$,

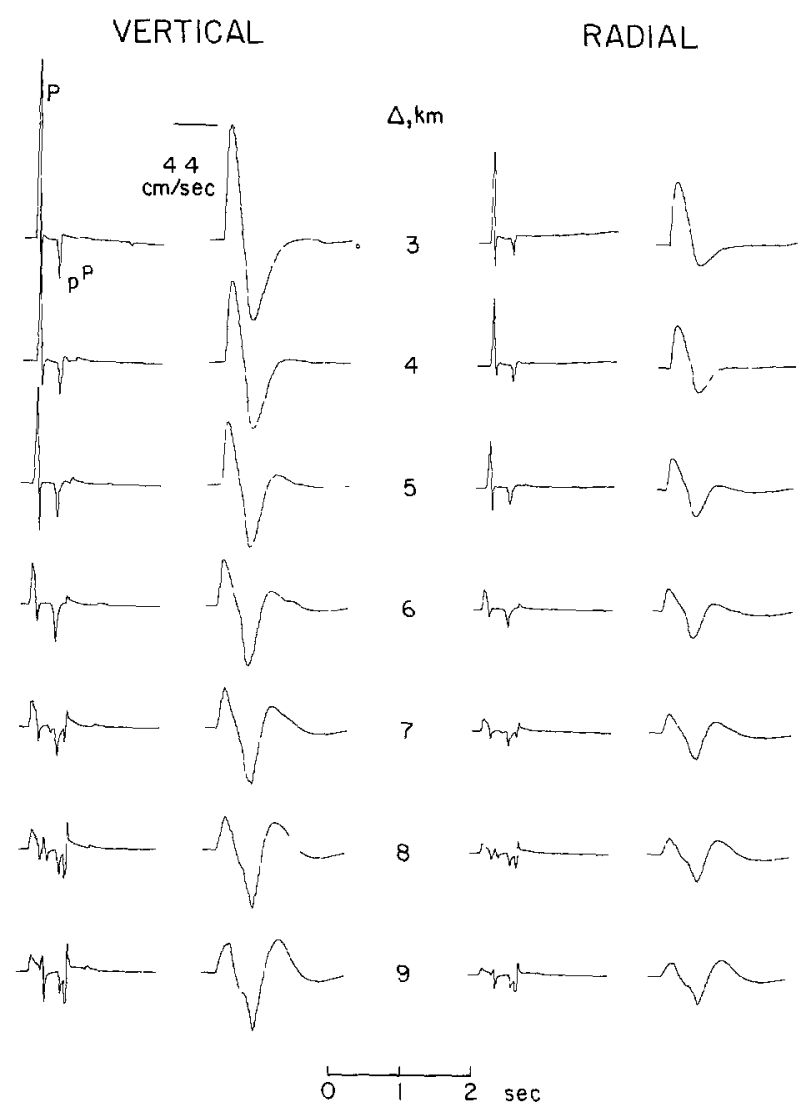

Fig. 6. Vertical and radial Green's functions and velocity responses assuming $(K=5, B=2)$ for the layered model given in Figure 5 . The amplitudes are scaled to the top trace Only $P$-mode generalized rays were included in these calculations. Numerical experimentation showed that rays containing $S$-wave legs contribute little to the early portion of the record. Rays encountering more than two internal reflections were neglected.

interacts with the overshoot feature of the source. Only generalized rays that arrive within the first second of motion have been included in these synthetics. Figure 7 shows a comparison of synthetic seismograms computed with various values of $K$ and $B$ with the observed vertical seismograms. Most of these fits could be considered adequate except, perhaps, for $(B=2, K=4)$, which is somewhat too broad. It should be noted that the ratio of radial to vertical motions shown in Figure 6 is about 0.45 , whereas the average for the data is somewhat lower, with considerable variation for the individual recordings (Figure 3). Also, note that when the downswing is particularly large, as on station 6 on Figure 3, the ratio of radial to vertical motion is relatively low. Thus, to gain some insight several additional models were studied. The results are displayed in the left two columns of Figure 8. Since the radial shapes were quite similar to the verticals, only the vertical component and the amplitude 
ratios have been plotted. First, note that increasing the shear velocity in the surface layer (hard top) greatly affects the ratio as well as changes the strength of $p P$. When the surface is soft (low-shear velocity), the phase $p P$ is strong because of the

I.

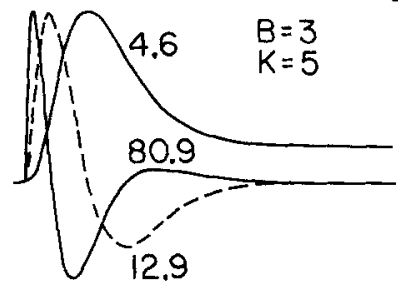

2.

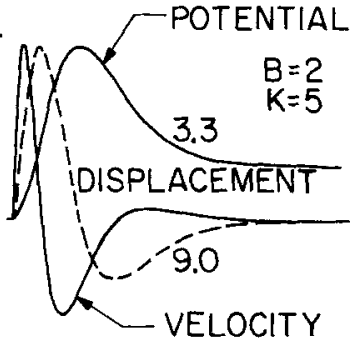

3.

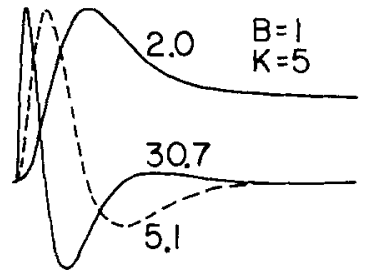

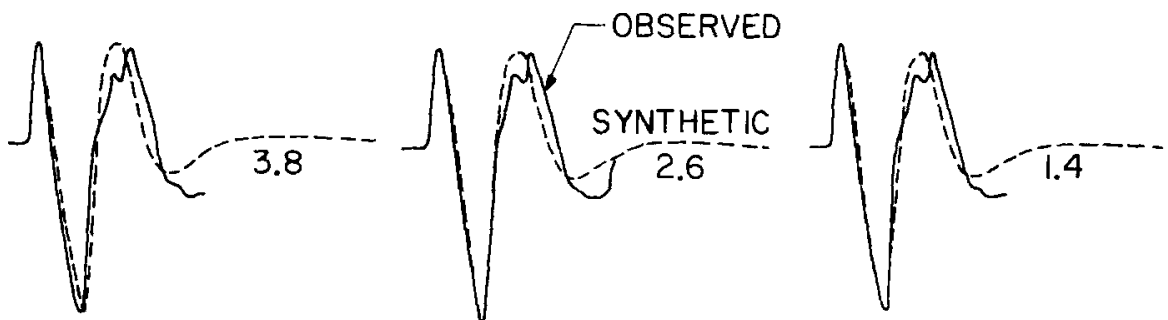

4.
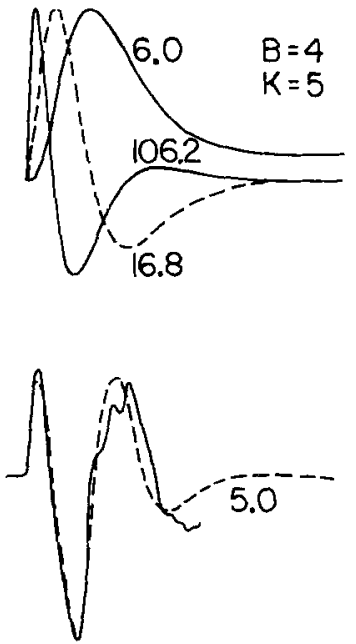

5.
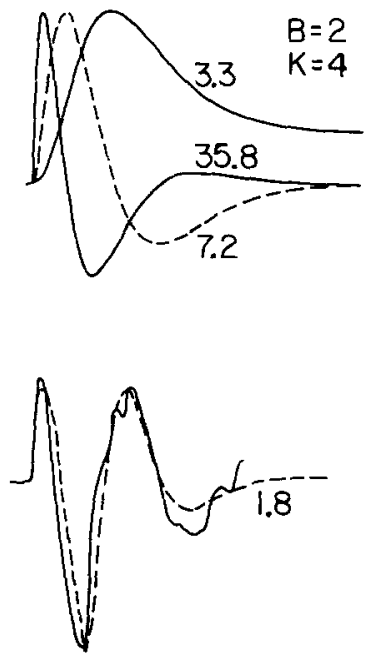

2

6.
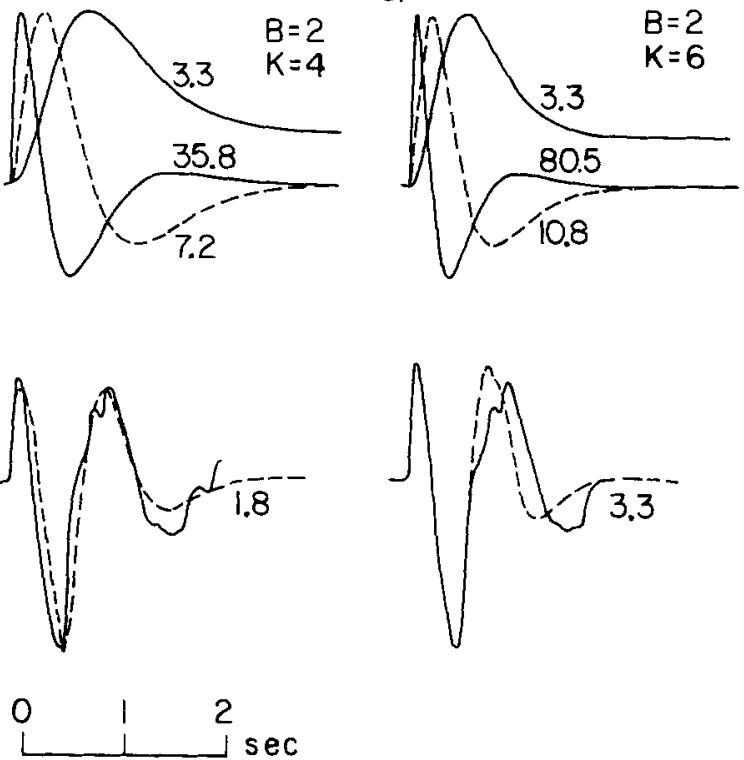

FIG. 7. The potential $\left(\mathrm{cm}^{3}\right)$ displacement $(\mathrm{cm})$ and velocity $(\mathrm{cm} / \mathrm{sec})$ for various assumed values of $K$ and $B$ are plotted in rows 1 and 3 where the numbers indicate peak values. The corresponding synthetic velocity and the average vertical observation (shown in Figure 3) are plotted in rows 2 and 4 .

weak conversion of $p S$ and because a soft surface has a strong effect on the receiver function. Thus, a strong $p P$ is compatible with a small ratio of radial to vertical and it appears that the waveforms shown on Figure 3 can be interpreted in this fashion. Another interesting feature that is common to the waveshapes in Figure 3 is a relatively broader upswing on the radial relative to vertical components. This feature is not particularly important to the objective of this study, but models that include 
rays that convert from $P$ to $S V$ near the receiver in a thin soft layer at the surface produce this effect. The radial component is strongly affected by these types of conversions, whereas the vertical component is rather insensitive.

To test the sensitivity of the synthetics of the choice of model parameters, Green's functions for a second velocity model were also computed. The new model replaces the lower three layers with a linear gradient, Figure 5. The computed Green's

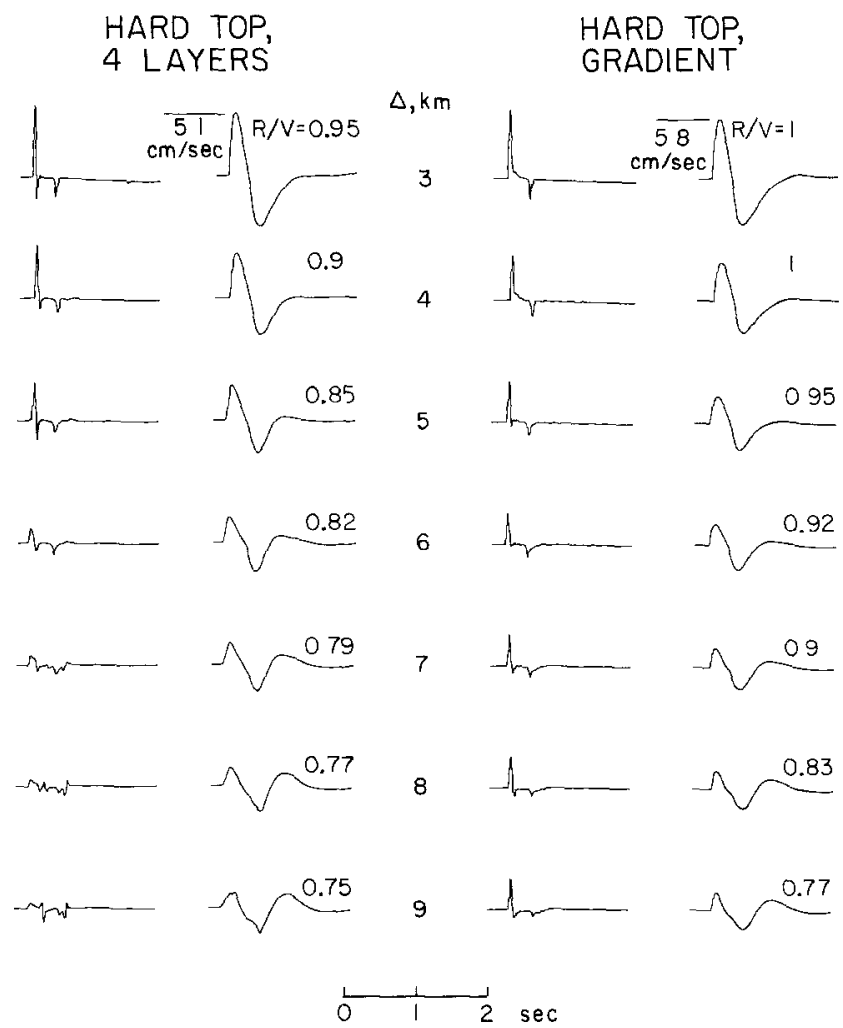

FIG. 8. Green's functions and synthetic velocity responses for $(K=5, B=2)$, assuming the layered model and smooth gradient model (simulated with 20 layers), both with the hard top. The amplitudes are scaled to the top trace.

functions are shown in the right side of Figure 8. Although the shapes of the new response functions are slightly different, the convolution of the longer period source function produces waveforms and amplitude ratios that are very comparable with the discrete model.

A problem that might affect these results would be the presence of thin highvelocity layers above the source. Such a structure could produce tunneling effects and strongly reduce the shorter period amplitudes. Fortunately, at $\Delta=8 \mathrm{~km}$, the turning velocity at the depth of greatest penetration approaches $3.8 \mathrm{~km} / \mathrm{sec}$ and this velocity should be sufficiently high to avoid that problem (see Mellman and Helmberger, 1974). If significant high-velocity layers are actually present above the source, then the source strength would be underestimated and the teleseismic $t^{*}$ would be slightly overestimated.

In conclusion, the crustal model below the shot point down to about $4 \mathrm{~km}$ controls the amplitude of the synthetics. The delay time of $p P$ is consistent with the model given in Figure 5. A smooth gradient model gives about the same results. Thus, 
$\psi_{0}(K, B)$ can be determined by simply scaling the synthetic given in Figure 7 to the observed waveforms. Assuming $K=5$, we obtain: $\psi_{0}(5,1)=3.1 ; \psi_{0}(5,2)=1.7$; and $\psi_{0}(5,3)=1.2$, all $\times 10^{11} \mathrm{~cm}^{3}$. Next, the teleseismic waveshapes and amplitudes will be compared with these local field results.

\section{Teleseismic Results: $t^{*}$}

The amplitudes of the teleseismic observations are listed in Table 1. The righthand column gives the amplitude corrected to $30^{\circ}$, i.e., removal of the geometrical

TABLE 1

\begin{tabular}{|c|c|c|c|c|}
\hline Station & Distance, $\Delta\left(^{\circ}\right)$ & Azamuth $\left({ }^{\circ}\right)$ & $\begin{array}{l}\text { Amplitude } \\
\quad(\mathrm{m} \mu)\end{array}$ & $\begin{array}{l}\text { Corrected } \\
\text { Amplitude } \\
(m \mu)\end{array}$ \\
\hline SCP & 30.0 & 71.2 & 823 & 823 \\
\hline OGD & 32.4 & 70.0 & 745 & 782 \\
\hline COL & 33.2 & 336.1 & 1074 & 1142 \\
\hline WES & 34.7 & 67.0 & 468 & 511 \\
\hline KIP & 39.9 & 2587 & 1097 & 1298 \\
\hline $\mathrm{BEC}$ & 42.4 & 80.7 & 845 & 1029 \\
\hline NOR & 54.8 & 10.2 & 182 & 255 \\
\hline KTG & 56.8 & 23.7 & 594 & 860 \\
\hline AKU & 59.9 & 28.3 & 365 & 548 \\
\hline NNA & 61.6 & 134.8 & 422 & 645 \\
\hline ARE & 68.2 & 133.1 & 1268 & 2131 \\
\hline ESK & 71.6 & 336 & 228 & 399 \\
\hline AFI & 72.8 & 236.7 & 548 & 980 \\
\hline NUR & 77.4 & 18.6 & 274 & 507 \\
\hline PTO & 77.8 & 47.3 & 342 & 639 \\
\hline TOL & 81.3 & 46.0 & 685 & 1352 \\
\hline STU & 81.7 & 32.9 & 251 & 491 \\
\hline PEL & 82.1 & 142.6 & 399 & 799 \\
\hline SHK & 83.9 & 3091 & 868 & 1779 \\
\hline SEO & 85.2 & 314.5 & 742 & 1521 \\
\hline NAT & 86.1 & 99.8 & 548 & 1151 \\
\hline GUA & 88.6 & 285.9 & 868 & 1870 \\
\hline HNR & 90.6 & 258.7 & 914 & 2021 \\
\hline
\end{tabular}

spreading effects for the more distant stations. Thus the amplitude at SCP is left unchanged whereas the amplitude at HNR, the most distant station, is substantially increased. The geometrical correction used in these computations is based on the curve displayed in Figure 3 of Langston and Helmberger (1975). The overall average of the corrected amplitudes is $1024 \mathrm{~m} \mu$, but there is considerable scatter with the more distant stations yielding the largest corrected amplitudes. The station geometry also imposes a strong correlation between azimuth and distance as can be seen from Table 1 and Figure 9. This obst.ved amplitude pattern could be the result of one or all of three mechanisms: (1) strong azimuthal radiation pattern imposed by structure in the source region; (2) effective amplification by the receiver structure for the island stations in the west and northwest azimuths; and (3) lateral variations in $t^{*}$.

The first mechanism is easily tested by comparing the amplitude behavior of several other events. Figure 9 shows the amplitude data for Jorum, Greeley, Boxcar, Benham, and Halfbeak. A constant scale factor has been applied to all observations 
for each source in order to minimize the scatter that results from various source strengths. The scale factors were simultaneously adjusted such that the scatter in the data at all stations for all sources was minimized. These events were located throughout the Silent Canyon Caldera. All five events show a consistent azimuthal trend. Figure 10 shows the waveforms and amplitude ratios for Jorum and Handley. The Handley test was located a few kilometers outside of the boundary faults associated with the caldera. Note that the waveforms are very consistent between these two tests and that the amplitude ratio is stable. Also, note that stations BHP and QUI have very complicated waveforms which are presumably caused by receiver structure. For this reason, we have omitted these two stations in our amplitude

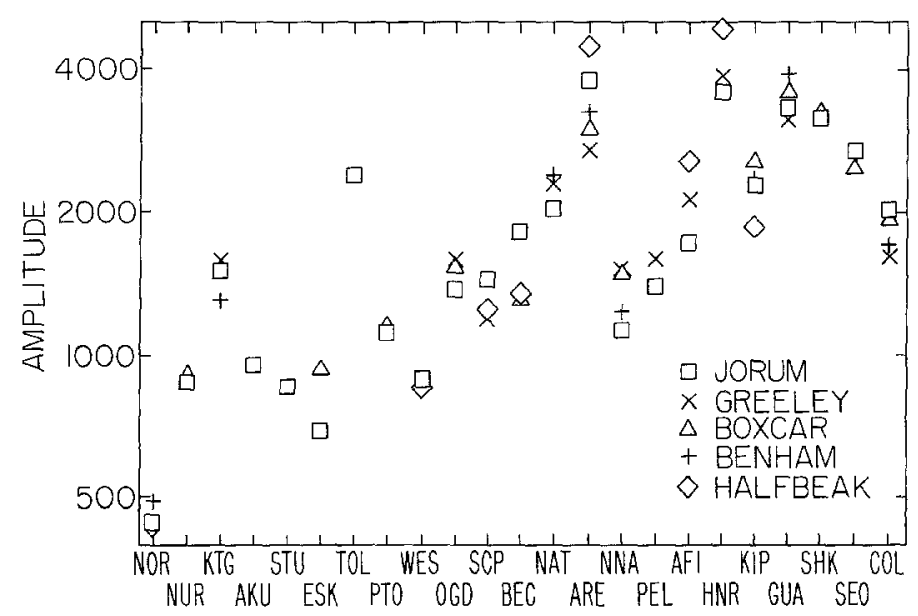

FIG. 9. Azimuthal variations in amplitudes as observed for five tests located throughout Pahute Mesa (NOR $=10^{\circ}, \mathrm{COL}=336^{\circ}$ ). The absolute amplitudes for each event have been adjusted in order to minumize scatter that results from variations in source strength. The station azimuths are listed in Table 1.

considerations although their neglect does not change the overall average (1024 $\mathrm{m} \mu)$ appreciably. We conclude from these data that near-source structure is not producing the amplitude pattern.

The question of systematic bias introduced by receiver structure is difficult to assess on a worldwide basis at this stage of study. Short-period records can show strong azimuthal patterns as discussed by Helmberger and Wiggins (1971), Aki (1973), and others. Based on the geology of many of the island stations, significant waveform distortion would not be too surprising. This may in part explain the pattern in Figure 9. Fortunately, the stations in the United States have been well studied by Butler (1979) and the receiver functions for the Eastern U.S. stations appear remarkably simple. Some of the recordings from these stations for the Jorum and Handley events are displayed in Figure 11. The long-period obsservations are quite small on the actual records, whereas the short-period observations are nearly off-scale making both difficult to digitize. Included at the bottom of Figure 11 are the best-fitting short- and long-period synthetics produced by varying $t^{*}$. In generating these responses, we used the crustal model at the source given in Figure 5 with the $P$-wave velocity below the $4.4-\mathrm{km} / \mathrm{sec}$ layer set at $5.0 \mathrm{~km} / \mathrm{sec}$. This is also the velocity assumed for the receiver half-space model. The amplitude of the synthetic can then be obtained from the theoretical curve given in Langston and Helmberger (1975) which contains the appropriate corrections for propagation through the lower 
crust and upper mantle. Variations in $K$ and $B$ were not particularly effective in changing the short-period amplitudes because changes in overshoot $(B)$ effect the source strength $\left(\psi_{0}\right)$ determination. That is, increasing the overshoot makes the short-period synthetics larger with constant $\psi_{0}$; but the source level is effectively

HANDLEY
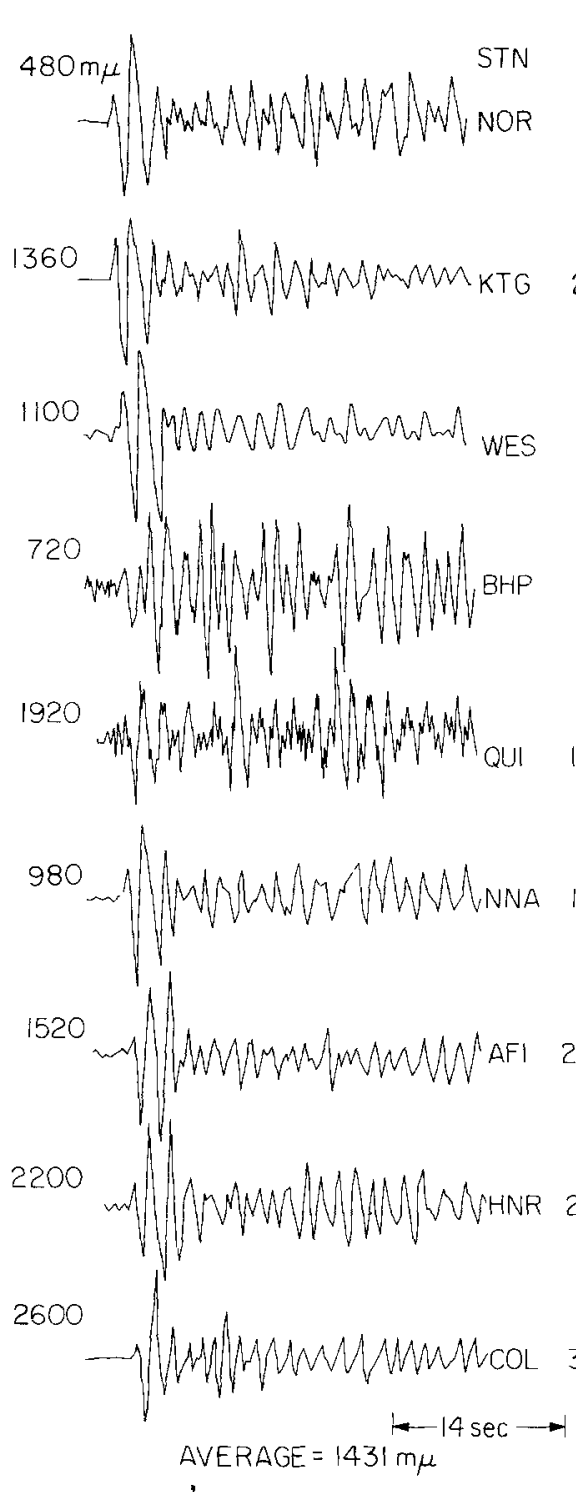

JORUM
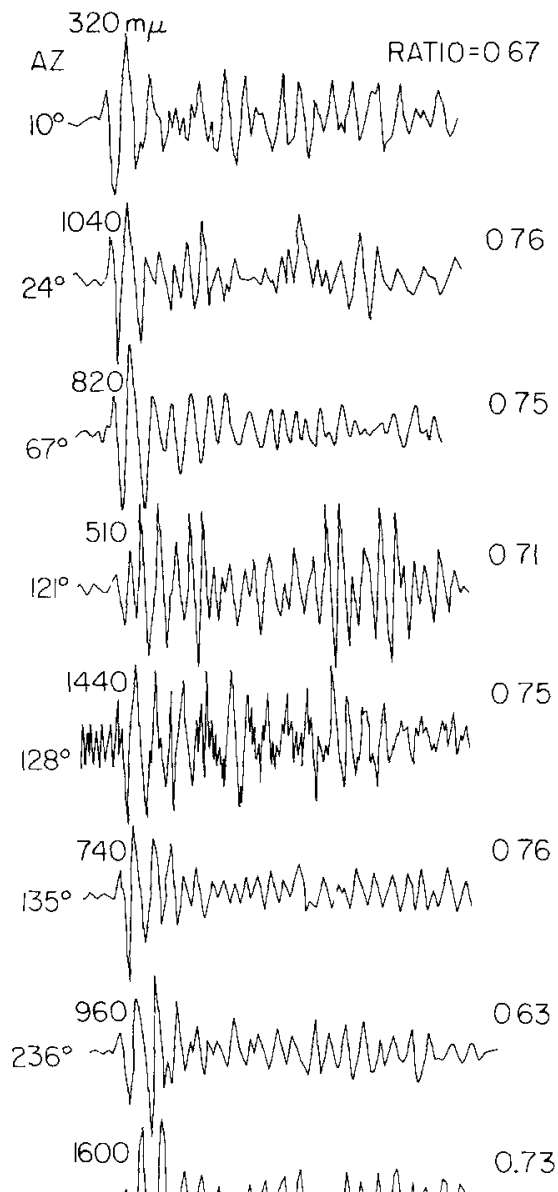

0.73

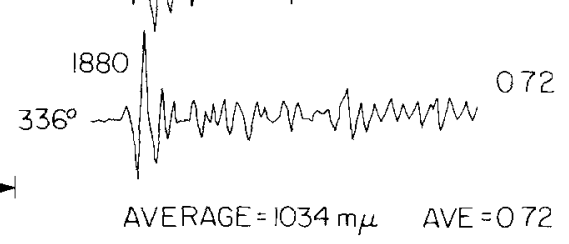

FIG. 10. Comparison of the observed teleseismic waveforms and amplitudes for the Handley and Jorum events.

smaller because of a compensating scale change required to fit the local amplitudes. Examples of these trade-offs are listed in Table $2(K=5, B=1,2,3)$. These synthetic teleseismic amplitudes, listed for a range of $t^{*}$ values should be compared with the worldwide short-period average of $1024 \mathrm{~m} \mu$ and the (SPZ/LPZ) ratio of 0.5 . Thus, we find that the uniqueness problem associated with the source description 

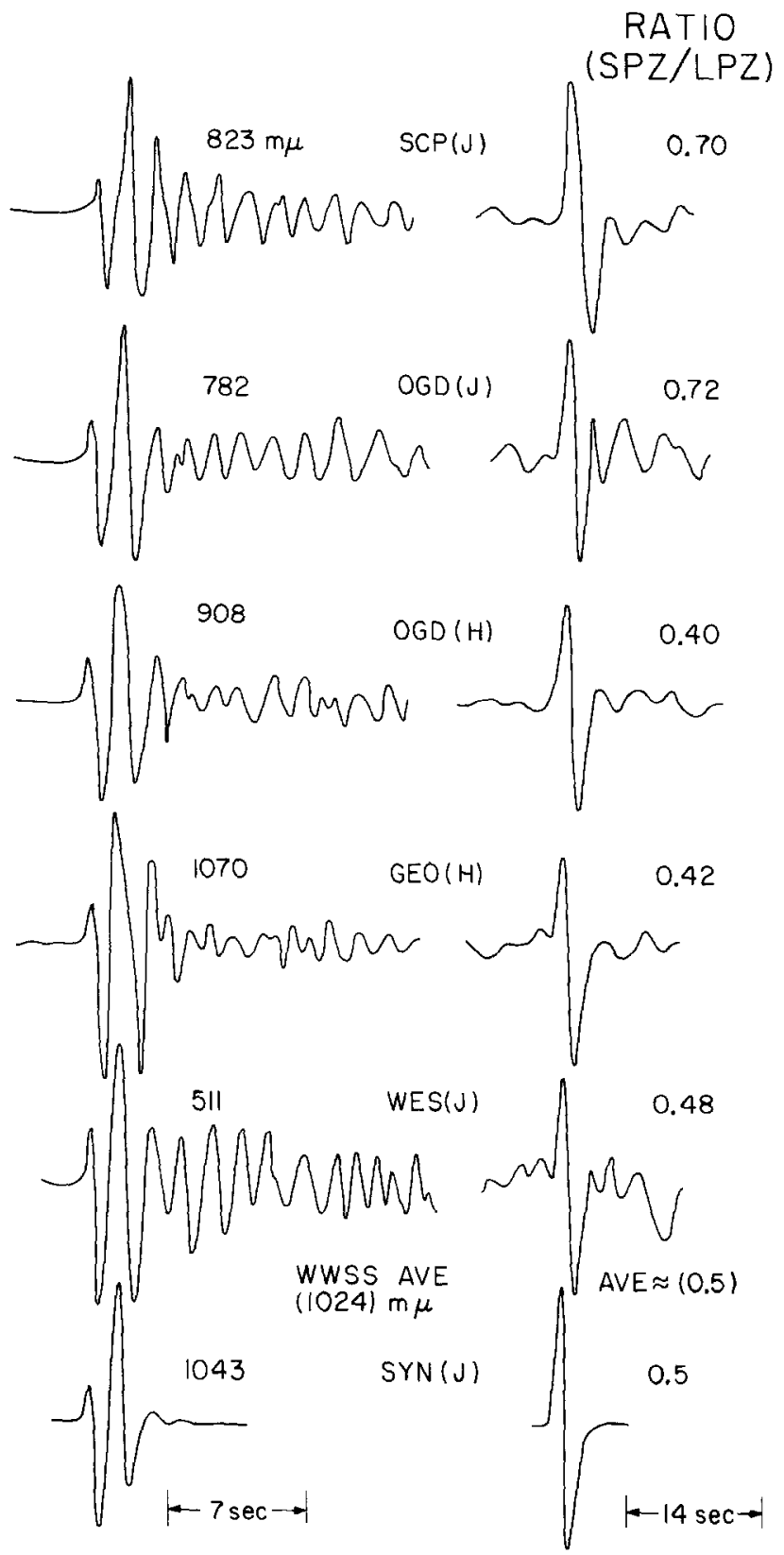

FIG 11 Comparison of the short-period (left) and long-period (rlght) waveforms from stations located in the Eastern United States with the synthetic seismograms, assuming $t^{*}=1.3$.

does not seriously influence the estimate of $t^{*}$ since the trade-off affects the local and teleseismic modeling in essentially the same manner.

\section{Discussion}

The average corrected amplitude for all short-period observations is $1024 \mathrm{~m} \mu$. If the local data is sufficiently removed from the high stresses involved in the explosion to be considered linear, and if the simplified crustal model is appropriate, then the best estimate of $t^{*}$ is 1.3 . This value is significantly larger than previous determi- 
nations, e.g., see Frasier and Filson (1972) and Der and McElfresh (1977). Those authors, working with digital data, find considerable amounts of high-frequency signal in some records. The observation of high-frequency energy in the teleseismic records requires a low estimate of $t^{*}$. One way to accommodate this apparent

TABLE 2

\begin{tabular}{|c|c|c|c|c|c|c|}
\hline \multirow[b]{2}{*}{$K=5$} & \multicolumn{3}{|c|}{ Amplitude $(m \mu)$} & \multicolumn{3}{|c|}{ (SPZ/LPZ) } \\
\hline & $B=1$ & $B=2$ & $B=3$ & $B=1$ & $B=2$ & $B=3$ \\
\hline \multicolumn{7}{|l|}{$t^{*}$} \\
\hline 0.8 & 3145 & 3162 & 3153 & 0.81 & 0.84 & 0.84 \\
\hline 0.9 & 2520 & 2507 & 2529 & 0.73 & 0.76 & 076 \\
\hline 1.0 & 2040 & 2028 & 2012 & 0.70 & 0.68 & 0.68 \\
\hline 1.1 & 1640 & 1643 & 1658 & 0.62 & 0.62 & 0.63 \\
\hline 1.2 & 1351 & 1350 & 1362 & 0.56 & 0.56 & 0.57 \\
\hline 1.3 & 1077 & 1084 & 1101 & 0.50 & 0.50 & 0.51 \\
\hline 1.4 & 898 & 902 & 913 & 045 & 0.46 & 0.47 \\
\hline 1.5 & 744 & 750 & 768 & 0.41 & 0.42 & 0.43 \\
\hline
\end{tabular}

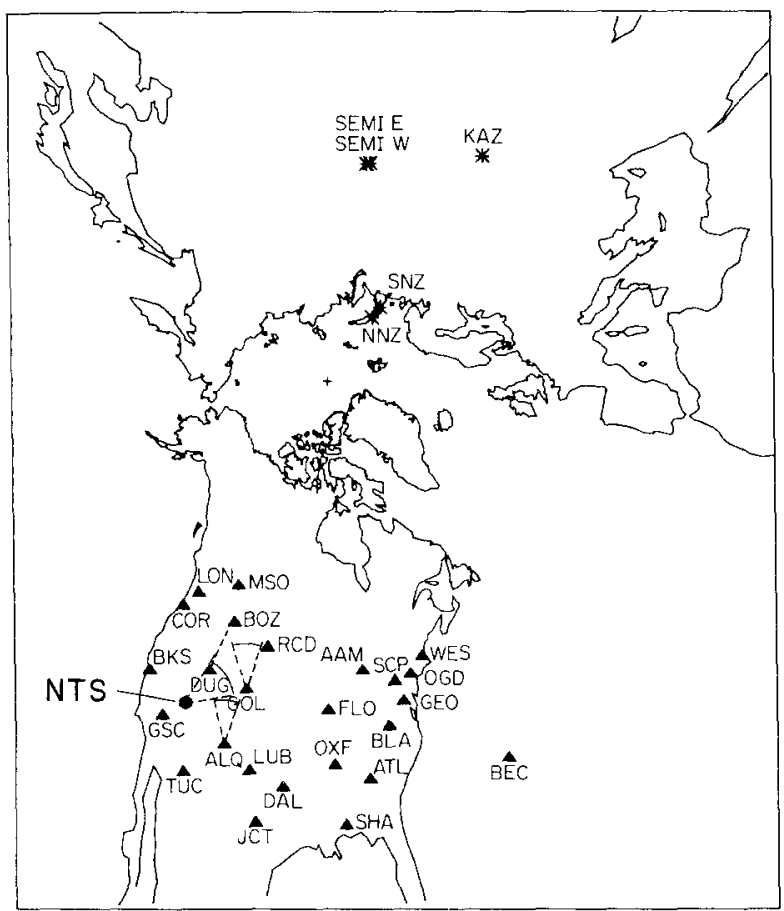

FIG 12 A gnomic projection (all great curcles are straight lines) showing the NTS, WWSSN stations of the United States, and the Soviet Union test sites (modified from Butler, 1979). Butler (1979) has observed a large seismic attenuation at the stations GOL and ALQ, relative to other United States stations from sources in both the Soviet Union and the Kuriles (dotted azımuths). Worldwide stations in a northeast azimuth from NTS are significantly reduced in amplitudes relative to other azmuths

discrepancy is to adopt a more general form of the attenuation operator such as discussed in Minster (1978). If seismic attenuation is frequency-dependent, then the $t^{*}$ value discussed above is appropriate for only the periods $\sim 1$ to $2 \mathrm{sec}$.

The $t^{*}$ derived in the present study is most appropriate for the frequency that dominates the $m_{b}$ measurement, i.e., $\sim 1 \mathrm{~Hz}$. The range of amplitudes observed.in 
Figure 9 could be interpreted as lateral variations in $t^{*}$ with the range of 1.5 for the northeastern azimuths and 1.1 for the northwestern. However, with the present data set it is impossible to uniquely differentiate real lateral variation in $t^{*}$ from apparent variations introduced by systematic bias in receiver structures. In a recent study by Butler (1979) of amplitudes at WWSSN stations in the United States from Soviet nuclear tests, it was found that stations in the Eastern United States do not show anomalously small amplitudes. However, the stations ALQ and GOL are depressed in amplitude by factors 2 to 3 . The same study found a similar result from earthquake sources in the Kuriles. These observations suggest as a hypothesis that the upper mantle along the ray paths near the stations ALQ and GOL is typified by low $Q$. Figure 12 is a gnomic projection showing the Soviet test sites and the United States WWSSN stations. Dashed lines from stations ALQ and GOL show the ray paths that are attenuated (Butler, 1979). Also shown on this figure is the range of azimuths from NTS that have been characterized in this study by low amplitudes and large $t^{*}(\sim 1.5)$. It is very intriguing that the two studies are at least consistent with a low $Q$ region in the upper mantle beneath the central Rocky Mountains. This model is clearly not unique and additional studies of the azimuthal receiver function characteristics of worldwide stations will be required to more fully understand the origin of the azimuthal amplitude anomalies associated with the NTS events.

\section{ACKNOWLEDGMENT}

We thank Robert $\mathbf{S}$ Hart and Jım Dewey who critically reviewed the manuscript. This research was supported by the Advanced Research Projects Agency of the Department of Defense and was monitored by the Arr Force Technical Applications Center under Contract F08606-79-C-0009, Srerra Geophysics Report SGI-R-79-006.

\section{REFERENCES}

Aki, D. (1973). Scattering of $P$ waves under the Montana Lasa, J. Geophys. Res. 8, 1334-1346.

Burdick, L. (1978), $t^{*}$ for $S$ waves with a continental ray path, Bull. Setsm. Soc. Am. 68, 1013-1030.

Burdick, L and G Mellman (1976). Inversion of the body waves of the Borrego Mountain earthquake to the source mechanism, Bull Selsm Soc. Am. 66, 1485-1499.

Burdick, L and D. Helmberger (1979). Time functions appropriate for nuclear explosions, Bull. Setsm. Soc. Am. 69, 957-974.

Butler, R. (1979). An amplitude study of Russian nuclear events for WWSSN stations in the United States, Quarterly Technical Report, SGI-R-79001, Sierra Geophysics, Arcadia, Calıfornia

Carpenter, E., P. Marshall, and A. Douglas (1967) The amplitude-distance curve for short-period teleseismic P-waves, Geophys J. 13, 61-70

Der, Z A and T. W McElfresh (1977). The relationship between anelastic attenuation and regional amplitude anomalies of short-period $P$ waves in North America, Bull. Seusm Soc. Am.67, 13031317.

Diment, W., D. Healey, and J. Roller (1960). Gravity and seismic exploration at the Nevada Test Site, U.S. Geol. Surv Profess. Paper 400B, B156-160.

Frasier, C. and J. Flson (1972). A direct measurement of the earth's short-period attenuation along a teleseismuc ray path, $J$. Geophys. Res 77, 3782-2791.

Haskell, N. (1967). Analytic approximation for the elastic radiatıon from a contained underground explosion J. Geophys. Res 72, 2583-2597.

Heaton, T. and D. Helmberger (1977). A study of the strong ground motion of the Borrego Mountain Californı earthquake Bull. Selsm Soc Am 67, 315-330.

Helmberger, D. and R Wiggms (1971) Upper mantle structure of midwestern United States, $J$ Geophys Res. 76, 3229-3245

Helmberger, D. and D. Harkrider (1972). Seismic source description of underground explosions and a depth discriminate, Geophys J. 31, 45-66.

Keller, G. (1960). Physical properties of tuffs of the Oak Spring Formation, Nevada, U.S. Geol. Surv. Profess. Paper 400B, B396-B400.

Langston, C. A. and D. V. Helmberger (1975). A procedure for modeling shallow dislocation sources, Geophys J. 42, 117-130. 
Mellman, G and D Helmberger (1974). High-frequency attenuation by a thin high-velocity layer, Bull Selsm Soc Am. 64, 1383-1388

Minster, J B. (1978). Transient and impulse response of a one dimensional linearly attenuating medium. II. A parametric study, Geophys $J$ 52, 503-524.

Orkild, P., D. Sargent, and R. Snyder (1969). Geologic map of Pahute Mesa, Nevada Test Site and vicinity, Nye County, Nevada, U.S. Geol. Surv., Misc. Geol. invest. map I-567.

Peppin, W. (1974). The cause of the body wave-surface wave discriminant between earthquakes and underground nuclear explosions at near-regional distances, $P h . D$. Thests, University of Californa, Berkeley, Californıa.

Spence, W. (1974). P-wave residual differences and inferences on an upper-mantle source for the Silent Canyon Volcanc Centre, Southern Great Basin, Nevada, Geophys J. 38; 505-523.

Springer, D. and R. Kinnaman (1971). Seismic source summary for U.S. underground explosions, 19611970, Bull. Setsm. Soc. Am. 61, 1073-1098.

Stump, B. W. (1979) Investgation of seisme sources by the linear inversion of seismograms, Ph.D. Thests, University of California, Berkeley, California.

von Seggern, D. and R. Blandford (1972). Source tume functions and spectra for underground nuclear explosions, Geophys. J. 31, 83-97.

Seismological LaBoratory

California Institute of Technology

Pasadena, California 91125 (D.V.H.)

Contribution No. 3317

Manuscrppt received April 12, 1980
SierRa Geophysics, INC

150 North Santa Anita Avenue

ARCADIA, California 91006 (D.M.H.) 